\title{
Summary of: Interactions in the dental team: understanding theoretical complexities and practical challenges
}

\section{FULL PAPER DETAILS}

'School of Dental Technology, The Dental Hospital, Richardson Road, Newcastle upon Tyne, NE2 4AZ; ${ }^{2} S$ chool of Education, University of Durham, Leazes Road, Durham, DH1 1TA; ${ }^{3}$ Senior Lecturer School of Dental Sciences (Retired), Newcastle University, Framlington Place, Newcastle upon Tyne, NE2 4BW ${ }^{*}$ Correspondence to: Dr Michael G. Reeson

Email:michael.reeson@nuth.nhs.uk

Tel: +44 (0) 1912825123

Refereed Paper

Accepted 9 July 2013

DOI: 10.1038/sj.bdj.2013.1046

-British Dental Journal 2013; 215: E16

\author{
M. G. Reeson, ${ }^{* 1}$ C. Walker-Gleaves ${ }^{2}$ and N. Jepson ${ }^{3}$ \\ VERIFIABLE CPD PAPER
}

Background Interdisciplinary collaboration and communication during dental training has become an increasingly influential idea within dental schools, both in the United Kingdom and European contexts. Research into this curriculum innovation has provided evidence to argue that benefits accrue both in terms of professional understanding and the development of dental professional learning dispositions. Objective This study investigates the interactions within a trainee dental team. In particular, the paper reports the professional experiences and development of trainee dental technicians and undergraduate dental students during a prolonged shared learning exercise in a combined UK university dental school and hospital. Methods Using a qualitative approach with a phenomenological framework, data sources included reflective diaries, focus group interviews and participant feedback. Results Eleven major domains were identified that accurately characterised the participants' beliefs, thoughts and practices. The results indicate that both trainee dental technicians and undergraduate dental students were pragmatic but positive in terms of their expectations of shared learning. In particular, they regarded the exercise as useful in terms of communication and understanding each other's role. Evidence also indicated the presence of original elements such as crisis of confidence and feelings of awkwardness that do not arise in other studies. Conclusions The implications for dental education are that for effective professional collaboration during training to take place a merger of interests among educators and policy developers in dental education must occur, and the challenges encountered within practice cultures must somehow be overcome. Therefore, more investment in evaluating research into interprofessional learning in dentistry would contribute to our knowledge about the place and role of interprofessional education in the professional dental curriculum and beyond.

\section{EDITOR'S SUMMARY}

Does the phrase 'trust fall' send a shiver up your spine? Then shudder still more at the thought of team assault courses, team blindfold driving and even team dance workshops. Yet these are just a sample of the many activities used all over the world in an attempt to build teams and help people learn to work together. Because, at the end of the day, teamwork is fundamental to making progress and getting things done.

In dentistry, teamwork is a part of everyday practice. Really it has always been so but it appears that collaboration in the dental team will be even more important to providing the best patient care in the future. In the UK for example, the GDC's 2013 guidance Standards for the dental team specifically addresses the requirement for all members of the dental team to work together in a way that is in the patients' best interests. Indeed the guidelines specify that team members must 'work effectively with your colleagues and contribute to good teamwork.'

If we know that dentists, nurses, hygienists and technicians (to name but a few dental team members) work together once qualified, should they not also learn together at university? This realisation is leading to an increase in shared learning initiatives in dental education. In these shared learning exercises, student dentists work with other dental team students, in this case dental technicians, to treat patients together.

In the course of shared learning, the aim is that the students not only learn practical skills through treating real patients but they also learn how their professional roles fit together to give these patients the best possible care. The authors of this paper investigated how these students reacted to working together at Newcastle Dental Hospital with a view to optimising shared learning for our future dentists and dental technicians. Interestingly, the students reported that they learnt from each other in the course of the exercise. They discovered not only how to provide better patient care but also how to make life easier for each other. Could our future dentists learn that from a 'trust fall'?

The full paper can be accessed from the $B D J$ website (www.bdj.co.uk), under 'Research' in the table of contents for Volume 215 issue 9.

Ruth Doherty

Managing Editor

DOI: 10.1038/sj.bdj.2013.1069 
TO ACCESS THE BDJ WEBSITE TO READ THE FULL PAPER:

- BDA Members should go to www.bda.org.

- Click the 'login' button on the right-hand side and enter your BDA login details.

- Once you have logged in click the 'BDJ' tab to transfer to the BDJ website with full access.

IF YOUR LOGIN DETAILS DO NOT WORK:

- Get a password reminder: go to www.bda.org, click the login button on the right-hand side and then click the forgotten password link.

- Use a recommended browser: we recommend Microsoft Internet Explorer or Mozilla Firefox.

- Ensure that the security settings on your browser are set to recommended levels.

IF YOU HAVE NOT YET SIGNED UP TO USE THE BDA WEBSITE:

- Go to www.bda.org/getstarted for information on how to start using the BDA website.
IN BRIEF

- Highlights the professional experiences of undergraduate dental students and trainee dental technicians during shared learning opportunities.

- Illustrates the issues related to collaborative working.

- Stresses the benefits of team working in delivering patient-centred care.

- Emphasises the importance of collaboration and communication within the dental team.

\section{COMMENTARY}

In the ever changing world of healthcare that includes dentistry it is becoming more important to understand team roles, communicate within a team and work as a team to deliver safe patient care at all times. ${ }^{1}$ In such an environment where practitioners have to be able to develop oneself to respond effectively to changes and regulator expectations, ${ }^{2}$ it is essential to embed best practice in training so a graduate becomes a 'safe beginner' ready to embrace the next transition into independent practice.

This paper provides an example of how shared professional experience affected the development of trainee dental technicians and undergraduate dental students during a learning exercise within a university dental school and hospital. They were encouraged to engage and be involved in each other's domain, be it the laboratory or clinic as a means to explore and gain experience of each other's roles. Each student was asked to keep a sessional structured reflective diary for a year and participate in focus groups and feedback. Essentially the authors wished to explore their experiences and how this impacted their learning and delivery of care for their patients at an early stage in their career.

The authors found three main themes arising from their time together. Firstly, apprehension and awkwardness, which was associated with knowing what was expected of them; the effect of belonging, fitting into the environment; and recognising the need to engage and participate, building good relationships through knowledge. Growth of the dental team was found to be gradual, enhanced through support, constructive dialogue, and sharing information and experiences to deliver effective and safe patient care. Worries about patient care were thought to have benefitted the care provided to patients during the study period.

In our current environment of professional practice driven by external and internal pressures, the experience of learning how to work as a team, being reflective and sharing responsibilities, as in this case between trainee technician and undergraduate clinician, fulfils many of the expectations of the regulator in terms of professiona $^{3}$ and education ${ }^{2}$ standards. As concluded the ability of healthcare professionals working collaboratively is critical to delivering patient centred care. The dental education system, through learning outcomes for primary registration and patient care pathways, will drive the very real need now for those developing dental curricula to recognise team working as being an essential part of professionalism and the dental team.

\section{Elizabeth S. Davenport}

Professor of Dental Education,

Barts and The London School

of Medicine and Dentistry

1. Independent Inquiry of the commissioning supervisory and regulatory bodies in relation to Mid-Staffordshire NHS Foundation Trust. Online information available at http://www.midstaffsinquiry.com (accessed August 2013).

2. General Dental Council. Preparing for practice: dental team learning outcomes for registration. London: GDC, 2005.

3. General Dental Council. Standards for the dental team. London: GDC, 2013.

\section{AUTHOR QUESTIONS AND ANSWERS}

1. Why did you undertake this research? Currently there is a paucity of research into shared learning between trainee dental technicians and undergraduate dental students, and arguably it is both a consequence and a reflection of the professional practice and learning impediments as well as the contested substantive nature of such curricula. To address shortcomings in the research literature, the purpose of this study was to gain an in-depth understanding of the experiences of trainee dental technicians and undergraduate dental students during shared learning opportunities and to examine whether interprofessional learning between these two groups of students offered any professional and occupational specific disciplinary developmental benefits or disadvantages.

\section{What would you like to do next in this area to follow on from this work?}

The current study did not seek to examine the benefits to patient care. Therefore, through the use of interpretative phenomenology in this study further research might use this framework to examine patient care. This might take the form of a longer term research study asking patients their views on whether having the opportunity to discuss their treatment options with more than one dental professional enhanced the quality of their care. Another area for future research could be the degree of shared learning that exists within European dental institutes. Future studies might also explore the influence of student characteristics, such as social class, cultural background, gender and age. 